DOI 10.37882/2223-2982.2020.11.27

\title{
СРЕДСТВА ВЫРАЖЕНИЯ АНОМАЛИИ В РУССКИХ ЗАГАДКАХ
}

\section{MEANS OF EXPRESSING ANOMALY IN RUSSIAN RIDDLES}

\section{A. Moiseeva}

Summary: Aim. This article is devoted to identifying and describing the means of expressing opposition «norm-anomaly» in Russian riddles. Methodology. The presentation of the article uses the structuralsemantic method of analyzing language units. An analysis of vocabulary with the prefix of non-and proposed-case forms of nouns with a preposition without, a classification of riddles with the semantics of «underdevelopment» and «objects of denial» is presented. Functional figurative elements illustrating deviations from the norm in riddles are understood.

Results. The analysis of language material showed that the means of expressing the opposition «norm-anomaly» are traced at different levels of the language: lexical, word-forming, morphological and syntactic. Research implications. The results of the study contribute to the theory of the linguistic category of evaluation.

Keywords: opposition «norm - anomaly,» means of expressing the anomalous, Russian, paremiological genres, small folklore genres, evaluation category.
Моисеева Анастасия Андреевна

Аспирант, Ульяновский государственный педагогический университет имени И.Н. Ульянова lunalita@inbox.ru

Аннотация: Цель. Данная статья посвящена выявлению и описанию средств выражения оппозиции «норма-аномалия» в русских загадках.

Процедура и методы. В изложении материала статьи используется структурно-семантический метод анализа языковых единиц. Представлен анализ лексики с приставкой без- и предложно-падежных форм существительных с предлогом без, производится классификация загадок с семантикой «недокомплекта» и «предметов отрицания». Осмысляются функциональные 0бразные элементы иллюстрирующие отклонения от нормы в загадках.

Результаты. Проведенный анализ языкового материала показал, что средства выражения оппозиции «норма-аномалия» прослеживаются на разных уровнях языка: лексическом, словообразовательном, морфологическом и синтаксическом.

Теоретическая и/или практическая значимость. Результаты исследования вносят вклад в теорию лингвистической категории оценки.

Ключевые слова: оппозиция «норма - аномалия», средства выражения аномального, русский язык, паремиологические жанры, малые фольклорные жанры, категория оценки.

\section{Введение}

$\Pi$ ословицы, поговорки, загадки и другие высказывания разговорного языка, называемые паремиями, содержат в себе этнокультурную информацию, в том числе о категории оценки и ее частотном значении, представленном оппозицией «норма-аномалия». Обыденное и невероятное гармонично сосуществуют в загадке - «единственном жанре фольклора, произведения которого посвящены незначительным, но постоянно присутствующим в жизни человека предметам и явлениям. Ни для какого жанра, кроме загадки, не представляет интереса простой сучок в бревне или доске, заслонка русской печи, оконное стекло, ледяная сосулька, ковш, иголка, ножницы и т.п.» [10; 44]. При этом самые простые и знакомые вещи, входящие в понятие нормы, описываются в загадках иносказательно, признаками и качествами зачастую парадоксальными. По замечанию О.Д. Суриковой, «оценка явления или понятия как аномального, эта лакмусовая бумажка аксиологической системы, неслучайно изучается на материале базовых паремиологических жанров - пословиц, поговорок и загадок. Аномалия находится в фокусе внимания тех и других - и это несмотря на принципиальную разницу в их жанровой природе» $[11 ; 388]$.
Если говорить о средствах выражения аномального и нормального, то в первую очередь следует отметить, что норма отражена в языке слабее, потому что обычно не вызывает эмоций. Причем отклонением от нормы может считаться любое отхождение в сторону от центра градационной шкалы, т.е. как, условно говоря, нечто плохое, так и нечто чересчур хорошее. Аномалия, «в отличие от нормы (если только норма контекстуально не воспринимается негативно, т. е. как аномалия, ср.: посредственный, так себе, средненький, звезд с неба не хватает и др.), представлена, как правило экспрессивными синонимами» [2; 9]. В языке богаче представлены явления, лежащие на противоположных концах градационной шкалы, чем т.н. «золотая середина». Еще в античности было замечено, что она не всегда имеет наименование. «Тот же, кто стоит посередине, не имеет названия, безымянны и (соответствующие) наклонности, за исключением честолюбия и честолюбца» $[1 ; 89]$.

\section{Семантика категории отрицания как признак отклонения от нормы}

Имеющий игровую природу жанр загадки воссоздает реальный мир по законам алогизма. Как текст по своей природе диалогический, загадка предполагает угадывание явлений и вещей действительно существующих, но 
зашифрованных метафорическим образом. Абсурд, алогизм и аномалия - центральный компонент загадки. При раскрытии истинного значения, спрятанного за этим компонентом, норма становится видимой.

Средства, иллюстрирующие аномалию в загадках, схожи с теми, которые обычно используются в пословицах и поговорках несмотря на то, что этот паремиологический жанр со временем лишился прямой дидактической функции. Загадка, «первоначально имея в виду не забаву, а поучение, принимала на себя обязанность в период мифический передавать из рода в род познания о всем, что считалось тогда великим и существенным» [4; 129].

Существует множество загадок, в которых нужно отгадать зашифрованный объект по необладанию необходимыми свойствами, т. н. «недокомплекту» [3; 82]. Например: Без рук, без ног, а ворота отворяет <Ветер> [10; 51]; Без окон, без дверей, полна горница людей <Огурец> [10; 59].

Чаще всего эта семантика находит воплощение в загадках с приставкой и предлогом без, относящимся к числу словообразовательных и грамматических средств, культурно и аксиологически маркированных. Согласно А.Ф. Журавлеву, «специальное лексическое выражение, концептуальное выделение с помощью особой единицы лексического состава получает отсутствие или недостаток не любого, но лишь весьма значимого объекта или качества» $[7 ; 12]$.

Как правило, загадки с семантикой «недокомплекта» строятся по двум логическим принципам:

1. Загадываемый объект не обладает определенными значимыми функциями (Без ног ходят <Часы> [10; 54]; Без рук на стену лезет <Щетка> [9; 157]);

2. Отрицается принадлежность объекта к тому или иному классу вещей, существ или явлений, но при этом ему приписываются свойственные им функции и признаки, иногда даже в избыточном количестве (т. н. «сверхкомплект») - (Два рога, а не бык, шесть ног без копыт <Рак> [6; 622]; Не огонь, а жжется, без рук рисует, без зубов кусает, без топора, без клинья мост мостил <Мороз> [8; 306]; Четыре ноги, да не зверь, есть перья, да не птича <Кровать> [10; 89]; Не куст, а с листочками, не рубашка, а сшита, не человек, а рассказывает <Книга> [13; 99]).

По мнению О.Д. Суриковой, «одной из «надежных» (с высокими шансами прочтения и отгадки реципиентом) и распространенных разновидностей метафоры является перенос по функции - а функциональны, разумеется, не абстракции, но конкретные предметы. Второе условие для ПО («предмет отрицания» - прим.), включенного в энигматический текст, - легкое «встраивание» его в систему отношений «часть - целое». Наконец, третий фактор, обуславливающий попадание образного элемента в загадку в качестве ПО и коррелирующий с предыдущими условиями, - вхождение соответствующего объекта в «ближний круг» внимания номинатора, его «повседневность» и доступность» $[11 ; 396]$. Последнее требование обусловлено тем, что эксплицитные признаки загаданного объекта должны быть метафорически связанными, но одновременно наглядными. Так, в загадках чаще всего используются образы, принадлежащие к сфере дома, например, хозяйственный инвентарь, посуда, одежда и т. д., или всем известные природные явления, такие как снег, дождь, мороз и т. п.

Среди тематических групп «предметов отрицания» обнаруживаются следующие:

- руки, ноги и другие части тела (Cmoum дуб без корня, без ветвей, сидит на нем птица врап; пришел к нему старик без ног, снял его без рук, заколол без ножа, сварил без огня, съел без зубов <Мороз> [10; 53]; Лежит без крыл, падает без ног; жарит его повар без огня, и ест его барыня без рта <Снег> [10; 54] );

- хозяйственный инвентарь (Дом без окон, без дверей <Гроб> [12; 181]; Без обручей, без дна стоит бочка вина <Яйцо $>$ [8; 89] );

- растительная тематика (Что без кореньев расmет? <Камень> [8; 75]; Что цветет без цвета? $<$ Сосна $>$ [8; 48]);

- одежда и рукоделие (Кто ткет без рук, без стана и без челнока? <Паук> [9; 36]; Летит тархан по всем торгам, без пол кафтан, без пуговии <Beтер> [8; 90]) и др.

Значительно реже встречаются загадки с зашифрованными в них абстрактными значениями, обозначающими «недокомплект». Исключениями являются упоминания «нематериальных» стихий, таких как ветер, вода, огонь и др. Например, как в загадке о воде: Без ветра, а шумит [10; 28].

Среди необходимых функций, которых может быть лишен загадываемый объект, по словам О.Д. Суриковой, чаще всего можно найти следующие:

1. Возможность трудиться (в связи с отсутствием инструментов, материалов или частей тела, которыми осуществляется труд): Сколотил заслон без топорища, без топора, без железного долота $<$ Мороз> [8; 305]; Без рук, без топоренка построена избенка <Гнездо $>$ [13; 77]

2. Возможность активно передвигаться (в связи с отсутствием рук, ног или крыльев): Без рук, без ног, а на печь лазит <Опара> [8; 78]; Ни глаз, ни ушей, а слепчов водит <Палка> [8; 111]; Без рук, без ног ползет на батог <Горох> [10; 60]; Ходит без ног, течёт, течёт - не вытечет <Река> [10; 54];

3. Возможность говорить и издавать любые звуки (в связи с отсутствием рта, языка, горла или голоса): Что без голосу? <Рыба> [10; 62]; Что говорит без языка, кричит без горла? [8; 158]. 
Кроме того, в загадках может отсутствовать способность жить, т. е. одушевленность, из чего возникает парадокс существования того или иного объекта (Живет без тела, говорит без языка, никто его не видит, а всякий слышит <Эхо > [12; 33]).

\section{Оппозишия «норма-аномалия» на словообразовательном, морфологическом и синтаксическом уровнях языка}

Вторым частотным средством иллюстрации аномалии в загадках является противительные союзы $\boldsymbol{a}$ или да в значении но. Таким образом синтаксически подчеркивается противоречие одной части предложения фактам, содержащимся в другой (Летит - молчит, лежит - молчит, а как умрет, так заорет <Снег> [8; 303]; Ног нет, $\boldsymbol{a}$ ходит, крылья есть, а летать не может <Рыба> [10; 63]; Красна, да не девка, хвостата, да не мышь <Морковь> [8; 123]; Не живой, а дышит <Опара> [8; 78]). При этом аномалия может иллюстрироваться как через отсутствие необходимых качеств и предметов, так и через их избыток. Например, в загадке про иголку Зверок с вершок, $\boldsymbol{a}$ хвост семи верст [10; 113] недостаток величины тела противопоставлен исключительной длине одной из его частей.

В ряде загадок исключительные, а значит аномальные, черты зашифрованного (и в действительности обыкновенного) объекта подчеркивается повтором отрицательных частиц: ни, входящей в состав союза ни... ни, или частицы не. Так в загадке Помер Адам, ни Богу, ни нам; ни душа на небо, ни кости в землю [10; 23] горшок метафорически представлен человеком, чье существование нарушает привычное течение жизни. Это описание соотносится с фразеологизмом «ни то, ни сё», семантика которого обозначает нечто невразумительное, аморфное и воспринимается скорее негативно, иными словами, как аномалия.

Подобным же образом строятся загадки с повторением частицы не. Загадываемый объект, к примеру, выпадает из традиционной гендерной модели (Cmoum дедюха в семи кожухах - не мужик, не баба <Пестик> $[10 ; 59]$ в связи со своей неодушевленностью, либо не соотносится с числом обычных людей в виду своего обособленного положения в обществе (Идет не мужик и не баба, несет не пирог и не сгибень, в этом пироге не творог и не рыба <Поп> [8; 330]).

На словообразовательном уровне встречаются «некомплектные» модели с суффиксами -еньк (Летом мох- натенька, зимой сучковатенька <Береза> [10; 56]; Маленька, светленька, весь мир одевает <Иголка> [10; 113]; Маленько, кругленько, а за хвост не поднять <Клубок> [8;102]; Маленький, удаленький сквозь землю прошел, красну шапочку нашел <Гриб> [10; 58]), суффиксами -к, -ик, - ок и др., указывающими на малый размер (Ha mычинке городок, в нем семьсот воевод <Коробочка мака> [10; 63]; Пал порошок, стал городок, краше Казани, краше Астрахани <Мак> [10; 162]; Штучка одноручка, носик стальной, хвостик деревянный <Коса $>$ [13; 88]). В последнем примере качественное несоответствие стандарту выражается также в слове одноручка через корень одн.

На уровне морфологии в загадках наблюдается использование моделей с отклонением от нормы в образовании степеней прилагательных (Что у нас выше леса стоячего, выше облака ходячего, краше мелких звезд? Что выше леса, краше света, без огня горит? <Солнце> [9; 47-49]; Взглянешь - заплачешь, а краше его на свете нет <Солнце> [9; 48]; Пал порошок, стал городок, краше Казани, краше Астрахани - [10; 162]).

На основе приведенных выше примеров можно также сделать вывод, что в одной и то же загадке порой соседствуют «некомплектные» и «сверхкомплектные» модели, тем самым усиливая ощущение парадокса (У барыни семьдесят семь платьев; выйдет на улицу - спина гола <Курица> [10; 65]; В брюшке - баня, в носу - решето, нос -хоботок, на голове - пупок, всего одна ручка без пальчиков, и та - на спине калачиком <Чайник> [8; 75]).

\section{Зак^ючение}

В загадках, как и в других паремиологических жанрах, отклонения от нормы иллюстрируются в основном функциональными образными элементами, «которые легко встраиваются в систему отношений «часть-целое» и находятся в «ближнем круге» внимания пользователя текстов. Это свидетельствует о том, что аномалия - в первую очередь всем известное целое, лишенное части, в большинстве случаев - функциональной, или ситуация, неполноценная из-за отсутствия необходимой составляющей (например, трудовая ситуация: строительство без топора, косьба без косы, шитье без иглы и проч.)» $[11 ; 401]$. Наряду с этим отклонения от нормы в загадках описываются через «некомплектные» и «сверхкомплектные» модели, наблюдаемые на разных уровнях языка, а также через несоответствия функций и признаков классу объекта или наоборот.

\section{ЛИТЕРАТУРА}

1. Аристотель. Собрание сочинений в 4-х томах. Т. 4. М.: Мысль, 1983. 550 с.

2. Артамонов В.Н., Уба Е.В. Аномалия как мотив наименования (на материале русских фамилий) // Вестник Московского государственного областного 
университета. Серия: Русская филология. 2019. № 1. С. 8-15.

3. Арутюнова Н.Д. Язык и мир человека. М.: Языки русской культуры, 1999. 896 с.

4. Буслаев Ф.И. Исторические очерки русской народной словесности и искусства, т. 1, СПб., 1861. 643 с.

5. Волоцкая 3.М., Головачева А.В. Языковая картина мира и картина мира в текстах загадок // Малые формы фольклора. Сборник статей памяти Г. Л. Пермякова / Сост. Т.Н. Свешникова. М., 1995. С. 218-255.

6. Даль В.И. Пословицы русского народа / В.И. Даль. - 2-е изд. - Санкт-Петербург: Типография М. О. Вольф, 1879. - Т. 2. - 654 с.

7. Журавлев А.Ф. Древнеславянская фундаментальная аксиология в зеркале праславянской лексики // Славянское и балканское языкознание. Проблемы лексикологии и семантики. Слово в контексте культуры. М., 1999. С. 7-32.

8. Загадки русского народа: Сборник загадок, вопросов, притч и задач / Сост. Д.Н. Садовников. М., 1996. 400 с.

9. Митрофанова В.В. Загадки / Отв. ред. Б.Н. Путилов. Л., 1968. 256 с.

10. Митрофанова В.В. Русские народные загадки / Отв. ред. В.И. Еремина. Л., 1978. 181 с.

11. Сурикова 0. Д. Аномалия как отрицаемая ценность (на материале паремий с предлогом и приставкой без) / 0. Д. Сурикова // Категория оценки и система ценностей в языке и культуре / отв. ред. С. М. Толстая. - М.: Индрик, 2015. - С. 387-402.

12. Русские народные загадки Пермского края: сборник фольклорных текстов с комментариями и истолкованиями / Сост. И.А. Подюков, А.В. Черных. СПб., 2012. $256 \mathrm{c}$.

13. Рыбникова М. А. Загадки. — М.; Л.: Академия

(c) Моисеева Анастасия Андреевна (unalita@inbox.ru).

Журнал «Современная наука: актуальные проблемы теории и практики»
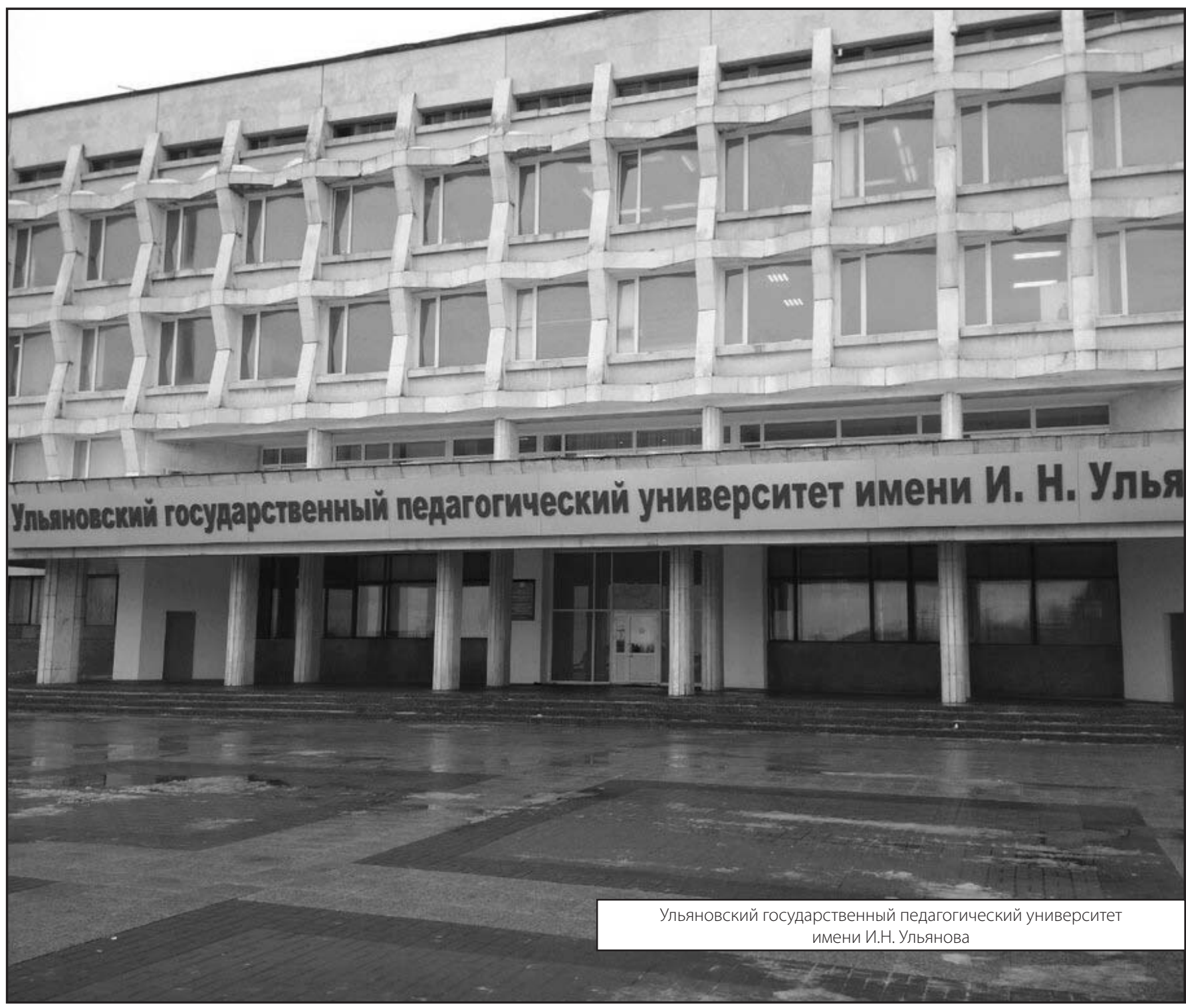